\title{
Impacts of Wind Power Variability on Generation Costs - An Overview
}

\author{
M. H. Albadi* and E. F. El-Saadany \\ Department of Electrical and Computer Engineering, University of Waterloo, 200 University Ave. W, Waterloo, ON, \\ N2L3G1, Canada \\ Received 23 May 2009; accepted 5 April 2010 \\ أثار التغيرات في طاقة الرياح على كلف توليد الكرباء -نظرة عامة \\ م·ح. البادي* و إ.ف السعدني \\ ملخصص : على الرغم من ان طاقة الرياح مصدر مستدام للطاقة وغير مضر للبيئة وغير مكلف نسبيا فان الاثار المترتبة على انظمة الطاقة الكهربائية- بسبب طبيعة

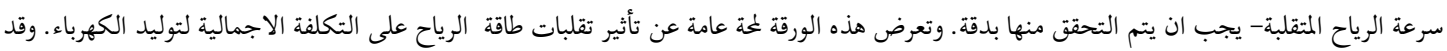

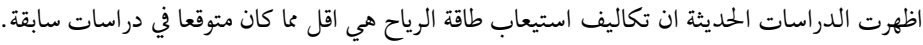 \\ كلمات البحث: تقلبات طاقة الرياح، تأثير طاقة الرياح على انظمة الطاقة الكهربائية، متطلبات استيعاب طاقة الرياح ، تكلفة استيعاب طاقة الرياح.
}

\begin{abstract}
Although wind power is sustainable, environmental friendly and relatively inexpensive source of electricity, the effects of its intermittent nature on power systems need to be carefully investigated. This paper presents an up-to-date overview of the impacts of wind power variability on overall generation cost. Recent case studies from different utilities around the globe demonstrated that wind integration costs are much lower than anticipated by earlier studies.
\end{abstract}

Keywords: Wind power variability, Wind impacts on power systems, Balancing requirements, Wind integration costs

\section{Introduction}

There is a strong growth in wind-installed capacity world-wide due to many reasons. On one hand, there is a public awareness and concerns about emissions, climate change and environmental issues about other competing source of energy. This encourages governments in many parts of the world to promote renewable sources of energy, including wind power, to provide part of electricity needs. Therefore, incentives and tax credits programs have been implemented in many countries to reach approved national and local Renewable Portfolio Standards (RPS). On the other hand, improved wind turbine technology results in lower costs of wind power.

In the year 2007 alone, $19.696 \mathrm{GW}$ of wind power capacity were added. By the end of December 2007,

\footnotetext{
*E-mail: mbadi@squ.edu.om

Currently working with Department of Electrical and Computer Engineering, College of Engineering, Sultan Qaboos University, PO Box 33, PC 123, Al-Khoud, Muscat, Sultanate of Oman
}

In the year 2007 alone, $19.696 \mathrm{GW}$ of wind power capacity were added. By the end of December 2007, the global installed capacity reaches $93.849 \mathrm{GW}$. Figure 1 shows the 13 countries that have $1 \mathrm{GW}$ or more installed capacity of wind generation in 2007 (World Wind Energy Association, 2008).

The fluctuation of wind power output is directly attributed to wind speed variations. These variations depend on changing climatic conditions and result in an intermittent and highly variable source of power. The intermittent nature of wind power represents a challenging constraint on power system operators as supply and demand need to be continuously balanced in real time. Therefore, the presence of any intermittent source of power, such as wind power facilities, increases balancing requirement and associated costs (Gil and Joss, 2006). 


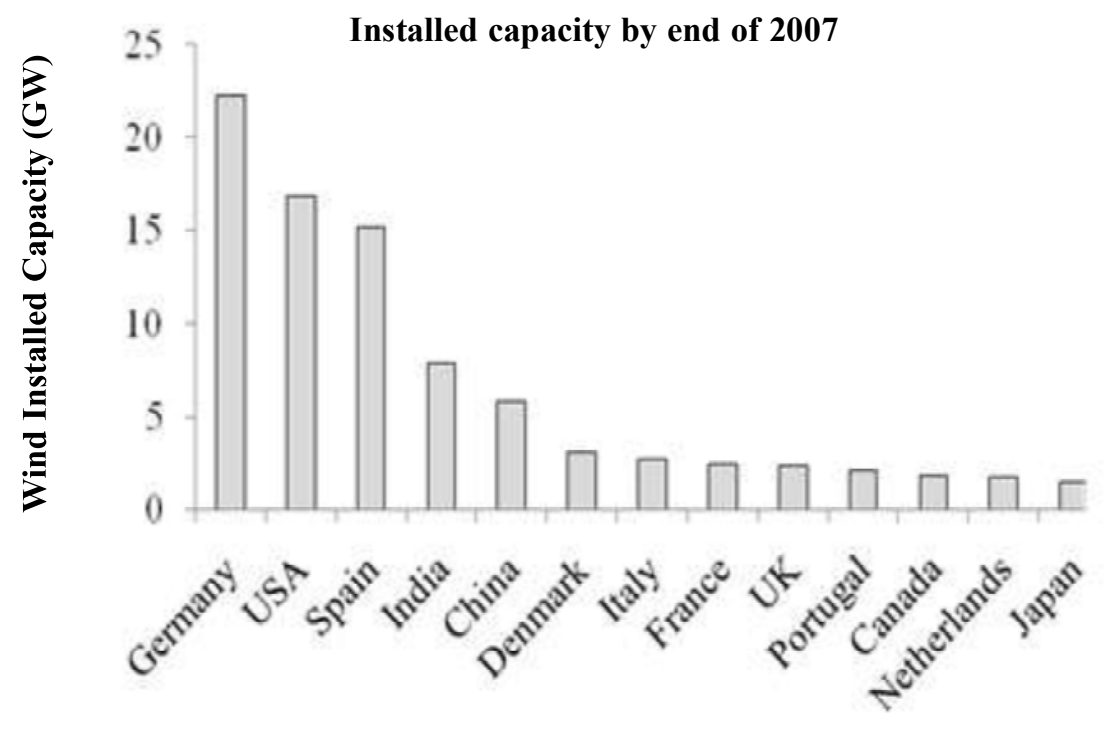

Figure 1. Countries having more than $1 \mathrm{GW}$ wind power installed capacity

Although integrating a large amount of wind power is technically possible, higher integration costs can be incurred when wind penetration level increases. Examples of areas currently having relatively high wind power penetration levels are West Denmark, North of Germany and Galicia in Spain. It is very decisive to accurately estimate the impacts and costs of wind power on the system operation when planning for high wind power penetration levels (Hilttinen, 2006).

After this introduction, wind power variability and its general impacts on power systems are highlighted. In Section 3, the paper discusses the effects of wind power on conventional generation costs. Experiences with high wind power penetration levels are summarized in Section 4, followed by specific conclusions.

\section{Wind Power Variability and Its Impacts}

\subsection{Reasons for Variability}

Wind speed is characterized by its high variability, both spatially and temporally. On a global scale, spatial variability is attributed to the fact that there are different climate regions on the world affected by the altitude and solar insulation. On a regional scale, wind speed varies according to the geographical location depending on the sizes of land and sea, and the presence of mountains and plain areas. In a local perspective, the type of vegetation and the local topography have a major role on wind speed (Ackermann, 2005).

At a given location, long-term temporal wind variability describes the fact that the amount of wind may vary annually. However, many studies estimated that the variation of mean wind power output from one 20year period to the next has a maximum standard deviation of $10 \%$ (Ackermann, 2005). Thus, the uncertainty of wind power production is not large for the lifetime of a wind turbine.

Seasonal variations are more predictable than annual ones. Wind speed synoptic variations associated with the passage of weather systems are not very predictable more than few days ahead. Wind variations with the time of day, which is called diurnal variations, are quite predictable.

Turbulences are variations of wind speed over minutes and seconds (Ackermann, 2005). This type of variations can affect power quality depending on both the network impedance at the point of common coupling and the type of wind turbine. Variable-speed turbines has a smoother power output compared to fixedspeed ones.

Diurnal and synoptic variations can affect power balancing requirements (Ackermann, 2005). Clear peaks corresponding to the synoptic, diurnal and turbulent effects have been presented in (Hoven, 1957) as shown in Fig. 2.

\subsection{Aggregation Effect}

Aggregation of wind turbine outputs reduces the temporal volatility of wind power by two aspects: increased number of turbines within a wind farm and spatial distribution of wind generation resources (Ackermann, 2005). On one hand, as the number of turbines within a wind farm increases, turbulent wind effect is dampen because wind gusts do not hit individual turbines at the same time. In fact, a small number of turbines ( $n$ ) are needed to achieve a significant smoothing effect, as the percentage variation of power output is reduced to $\mathrm{n}^{-1 / 2}$, ideally. On the other hand, a wider geographical dispersion of wind farm reduces the impact of diurnal and synoptic variations. Spatial distribution of wind farms with certain aggregated capacity has a much lower up and down ramping rate requirements compared to a large single wind farm 


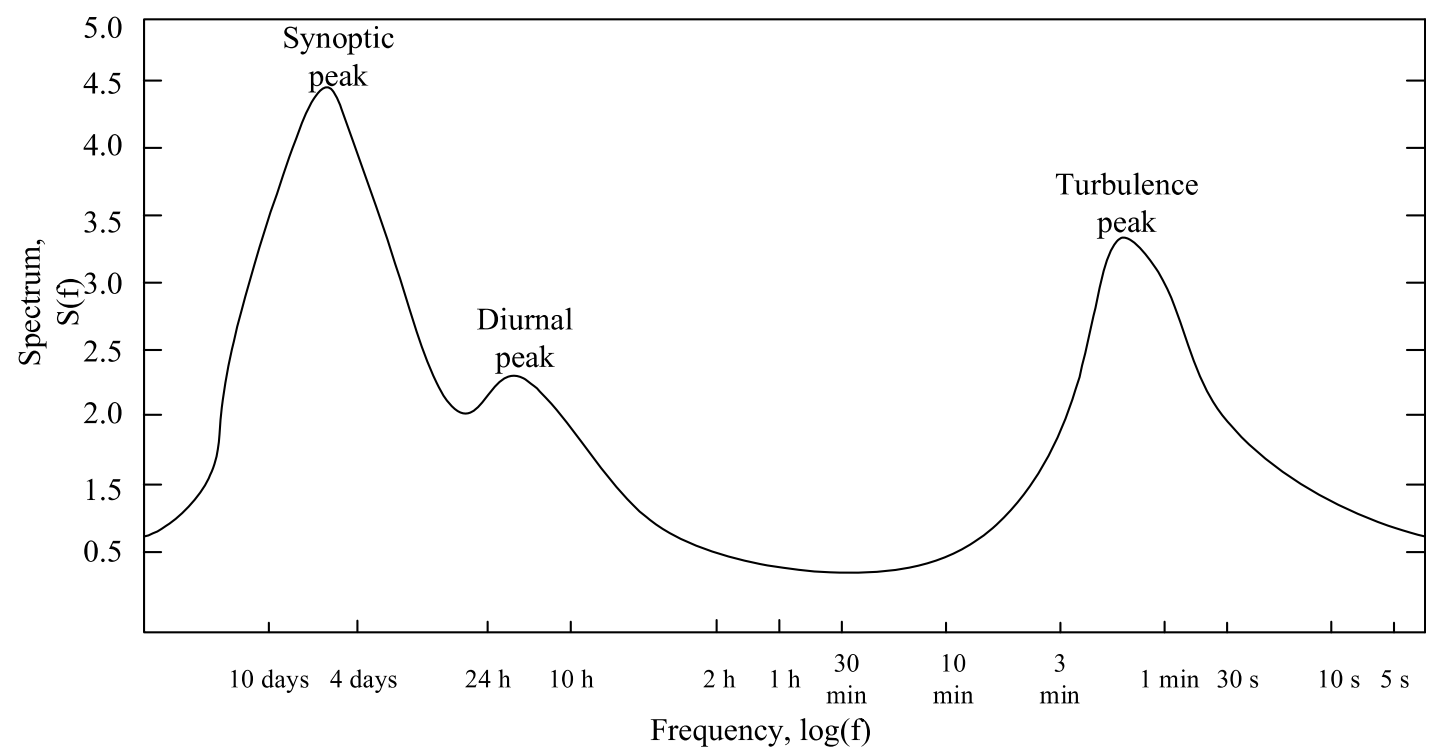

Figure 2. Wind spectrum at farm brookhaven national laboratory

Table 1. Wind speed variability summary

\begin{tabular}{|c|c|c|c|}
\hline & Predictability & $\begin{array}{c}\text { Aggregation } \\
\text { effect }\end{array}$ & $\begin{array}{c}\text { Impacts on Power } \\
\text { Systems }\end{array}$ \\
\hline Annual & Not predictable but Small & NA & \multirow{2}{*}{ Reliability / Adequacy } \\
\hline Seasonal & Predictable & limited & \\
\hline Synoptic & Predictable few days ahead & \multirow{2}{*}{$\begin{array}{l}\text { Through wider } \\
\text { geographical } \\
\text { dispersion }\end{array}$} & \multirow{2}{*}{$\begin{array}{l}\text { Unit commitment / } \\
\text { Reserves }\end{array}$} \\
\hline Diurnal & Predictable & & \\
\hline Turbulences & Not predictable & Ideally $n^{-1 / 2}$ rule & Power Quality \\
\hline
\end{tabular}

having the same capacity (Ackermann, 2005). For Example, it has been reported that the combination of wind power outputs from 17 geographically dispersed sites in Ontario is estimated to reduce the variability of the aggregated wind power output about $60-70 \%$ compared to the output from one site, for 10-minute and 1hour data (TrueWind, 2005). Table 1 presents a summary of the sources of wind power temporal variation and relevant impacts on power system operation.

\subsection{General Impacts of Wind Power}

The impacts of wind power integration on any power system depend on two main factors: penetration level and systems flexibility (Ackermann, 2005). In general, increased wind penetration will increase the impacts perceived by the system. On the other hand, systems which are inherently more flexible than others will be able to accommodate more wind power without perceiving unwanted impacts from wind generation facilities.

Smith et al. reported that the existing case studies have explored wind capacity penetrations of up to $20 \%$ to $30 \%$ of system peak and have found that the primary considerations are economic, not physical
(Smith et al. 2007). This is summarized by how to deal with wind power uncertainty and variability. The first step to increase wind power penetration level is to understand and to quantify its impacts on utility systems. In addition, wind power plants design and operation, power systems design and operation, and market rules have great influence in accommodating wind power.

There are two types of wind power impacts on system operation: short-term and long-term impacts. Short-term impacts deals with operational time scale whereas long-term impacts involve planning for peak load periods. Short-term wind integration impacts involve system balance related issues, which are represented by requirements and costs related to the fluctuating wind power. The main impacts of wind power on power systems are listed below.

\subsubsection{Generation Efficiency}

Fluctuating wind power affects other conventional dispatchable generation units. Intermittent performance of wind power leads to the fact that conventional units might operate in a suboptimal unit commitment. This problem can be reduced by accurate wind produc- 
tion forecasting and prediction. However, even with good forecasting and prediction tools, fluctuation of wind power causes less efficient operation of thermal units (Ackermann, 2005). The costs of high wind penetration on thermal units have been studied in (Smith et al. 2007). The cost of reduced generation efficiency on the system depends on the initial unit commitment of conventional units, wind power uncertainties, and system flexibility.

\subsubsection{Reserves}

A back up reserves for regulation (1-minute), load following (5-minute) and operating reserve (10minute) are needed to account for wind power fluctuations. The main factors that affect the amount of required reserves are initial load variations, the size of the balancing region, and the geographical dispersion of wind power resources. Ontario case study (Energy, 2006) presents a good example of reserve requirements as a function of wind penetration. Normally, the 1-munite regulation requirement is not of concern, even with high wind penetration level, due to aggregation and spatial distribution of effect.

\subsubsection{Curtailed Energy}

In some cases wind turbines' output needs to be curtailed to preserve balanced, stable and secured operation of the grid. In low load periods, system operator may consider wind power curtailment to ensure that enough dispatchable resources are online to guarantee enough reserves and ramping capabilities in order to accommodate demand's fluctuation (Energy, 2006). In other cases, the operator will order wind power curtailment when wind power is high, local demand is low and transmission lines to other areas are approaching their thermal limits (Ackermann, 2005). The need to curtail some wind power output depends not only on penetration level, but also on system flexibility. This flexibility can be enhanced by introducing more Demand Side Management (DSM) or Demand Response (DR) programs.

\subsubsection{Reliability}

Variable sources can be relied on in supplying peak demands if their patterns are correlated with that of the demand, an example would be solar power and air conditioning demand. Normally, wind power has no correlation with the load in many parts of the world. For example, Ontario, which is a summer peaking utility, has more wind power in winter than in summer (Inc 2006). Even with winter peaking utilities, there is no guarantee that wind power will be available when needed most (peak periods). Policy makers should be careful in estimating capacity value of wind power. Large wind power penetration will need large amounts of conventional plant to ensure supply adequacy and security (Ilex and Umist, 2002). Additionally, the reliability of power systems that have high wind power penetration levels is affected by original load demand, the geographical dispersion of wind power resources, the available transmission capacity, and the system flexibility.

\subsubsection{Transmission and Distribution Losses}

Wind power can increase or decrease network losses (transmission and distribution) depending on the wind power penetration level, the correlation between wind production and load profile, and the location of wind energy resources relative to load centers (Quezada et al. 2006). Moreover, high wind penetration levels may result in higher transmission capacity requirements; consequently, higher transmission losses. Transmission congestions can occur when wind generation is away from loads (Ilex and Umist, 2002).

\subsubsection{Voltage and Reactive Power}

Induction generators used in wind turbines inherently absorb reactive power from the grid. Fluctuations in power output results in voltage fluctuations when using fixed speed turbines. However, modern variable speed turbines, such as Doubly Fed Induction Generators (DFIGs), can provide reactive power support using appropriate interfacing (Ackermann, 2005).

\section{The Effect of Wind Power on Genera- tion Costs}

Although it is technically possible to integrate a large amount of wind power, higher wind penetration levels normally results in higher integration costs. West Denmark, North of Germany and Galicia in Spain are examples of areas that have a relatively high wind penetration levels. In West Denmark, which has a wind power penetration level (maximum wind production/peak demand) of $58 \%$, about $24 \%$ of consumed energy comes from wind power generation facilities (Soder et al. 2007).

The general approach of evaluating wind power impacts on the system is by evaluating the physical impacts of wind on the system and calculating the consequent costs. This process involves obtaining wind data that represents the actual performance of wind power plants. Each potential wind power plant location is represented by sets of virtual anemometers that are used for power production calculations (Corp and Inc 2004).

Most wind integration studies divide wind impacts into the four time frames corresponding to that of system operation: namely, regulation, load following, scheduling and unit commitment; Fig. 3. The net load, which is the load minus wind production, should be 

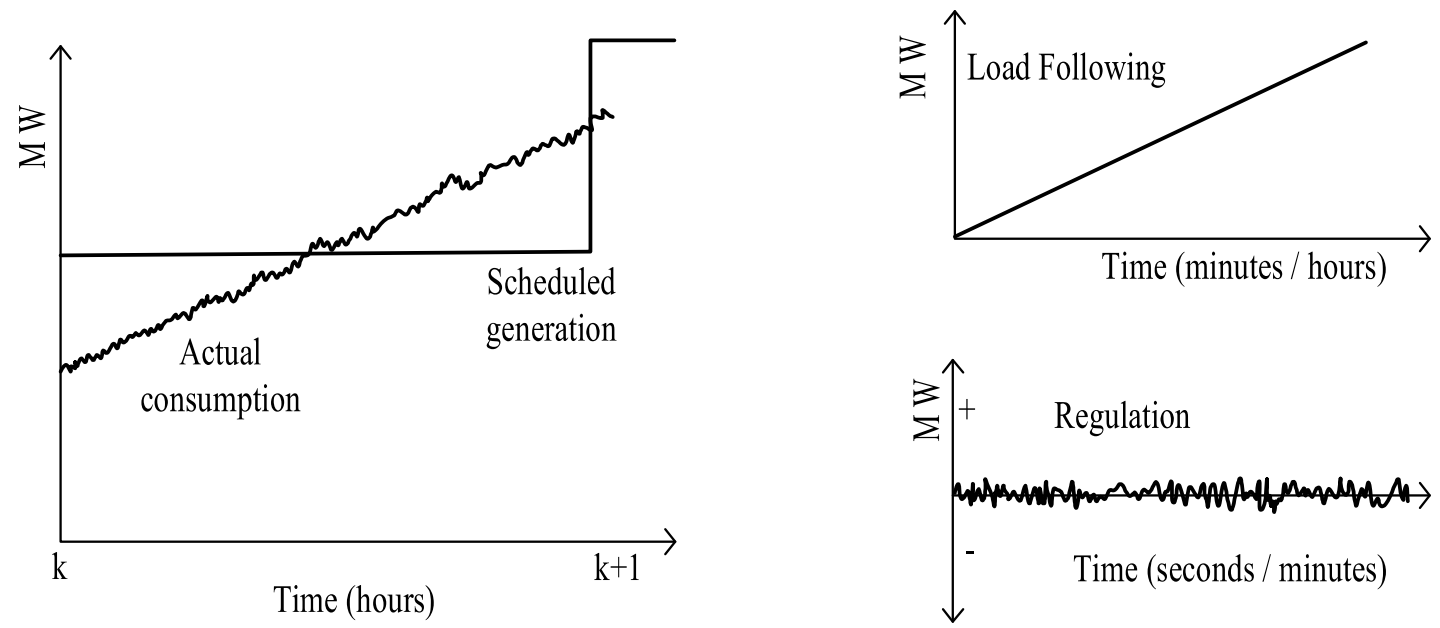

Figure 3. Operation time frames

Table 2. Down of reserve costs attributed to wind power

\begin{tabular}{|c|c|c|c|c|c|}
\cline { 3 - 6 } \multicolumn{2}{c|}{} & \multicolumn{4}{c|}{ US\$/MWh } \\
\hline Study & PL (\%) & R & LF & UC & Total \\
\hline WUIG/Xcel & 3.5 & 0 & 0.41 & 1.44 & 1.85 \\
\hline PacificCorp & 20 & 0 & 2.5 & 3.00 & 5.50 \\
\hline BPA & 7 & 0.19 & 0.28 & $1.00-1.80$ & $1.47-2.27$ \\
\hline We Energies II & 29 & 1.02 & 0.15 & 1.75 & 2.92 \\
\hline
\end{tabular}

served to maintain system balance for all time frames. In regulation, short term reserve capacity is needed to maintain demand-generation balance, and usually performed by automatic generation control (AGC) of some designated generating units within seconds to few minutes. Load following is in the range of 10 minutes up to several hours, and includes morning ramp-up and evening ramp-down capabilities. In scheduling and unit-commitment, the operator objective is to ensure that sufficient generation is available for hours and days ahead, respectively, of the real-time operation. The system operator should make sure that operating reserves are sufficient to maintain system balance according to local reliability standards $e g$. North American Electric Reliability Council (NERC) standards (NREC, nerc.com).

Initially, it was thought that operational impacts of wind generation will cost utilities about $\$ 15$ to $\$ 20$ per MWh of wind energy. However, recent studies concluded that additional reserve capacity needed to integrate wind generation is at most $10 \%$ of the total wind plant nameplate capacity and in most cases, between $3 \%$ and 5\% (Gil and Joss, 2006). The results of many case studies developed in Europe and North America estimated that the resulting operating costs are between \$2 and \$4 per MWh for low wind power pen- etration levels and increase up to \$6 per MWh for high penetration levels. These amounts, which represent the cost balancing operations, should be reflected on integration fees designed by utilities for wind projects.

Regulation impacts of spatially distributed wind generation facilities are expected to be modest due to smoothing effect of uncorrelated short term wind production. For Example, it has been reported that the addition of $1500 \mathrm{MW}$ (10\% of peak demand) and 3300 MW (15\% of peak demand) of wind in the US increased the regulation requirements by $8 \mathrm{MW}$ (Zavadil et al. 2004) and 36 MW (Energy, 2005), respectively.

The load-following impacts of wind are attributed to increased net load variability compared to original load variability. All wind integration impacts studies concluded that the distribution of the net load changes flatten and expand with large scale wind integration. This means an increase in ramping requirements for longer hours of the year.

As seen in Table 2 (Smith et al. 2004), the dominant balancing cost component is related to the unit commitment time frame in which decisions must be made about which units to start and stop and when to do so to maintain system reliability at minimum cost (Holttinen, 2006). Wind integration introduces uncer- 

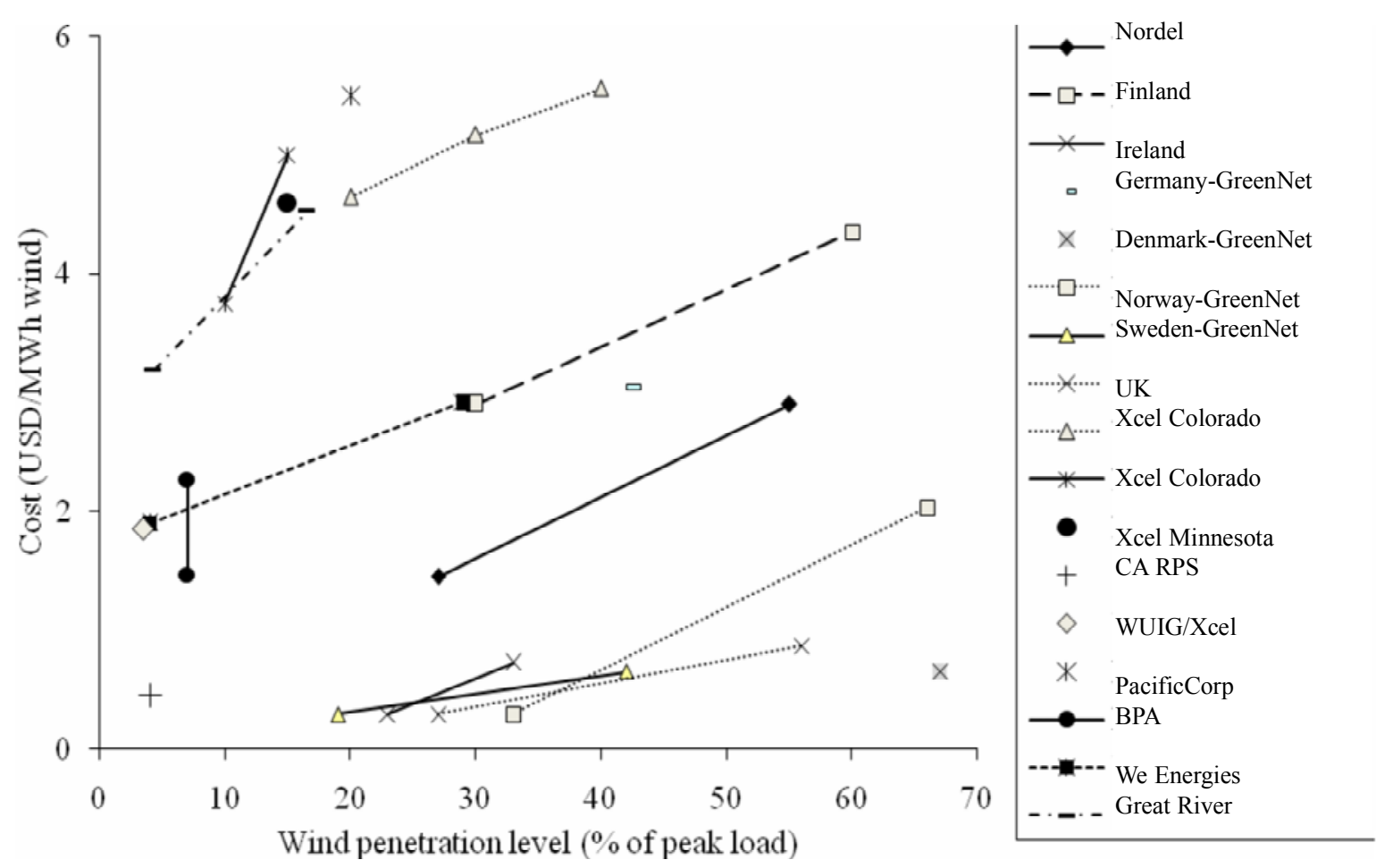

BPA, UWIG/Xcel, We Energies, PacificCorp, and Great River data is from [2];

Nordel, Finland, Ireland, GreenNet studies, and UK data is from[3];

WUIG/Xcel, PacificCorp, BPA, We Energies, Great River, and CA RPS data is from [8].

Figure 4. Wind power balancing requirements related costs. (Currency conversion rates 1 Pound $=1.95$ US\$ and 1 Euro $=1.45$ US \$)

tainty into the day-ahead unit-commitment process. This impact results in an increase in the operating cost up to $\$ 5$ to $\$ 6$ per MWh of wind power production at wind power level of 20 to $30 \%$. This increase in cost varies depending on flexibility of generating units, fuel cost, market regulations, and both load and windgeneration resources characteristics. Wind power forecasting can significantly reduce costs associated with day-ahead uncertainty. Smith et al. reported that the state-of-the-art commercially available forecasting tools can provide $80 \%$ of the benefits that would have been achieved from perfect forecasting (Smith et al. 2004). Moreover, the authors of (Ummels et al. 2007) concluded that forecasting error does not have a significant impact on thermal units operating costs.

\section{Wind Integration Cost Summary}

The results of many studies of wind integration costs that are related to balancing requirements presented in (World Wind Energy Association, 2008; Gil and Joss, 2006) and (Smith et al. 2007) are compiled in Fig. 4. As demonstrated by the figure, these results are scattered and quite difficult to compare. The scattering is attributed to different methodologies used, data and tools used, terminology and metrics in representing the results, as well as system characteristics (Holttinen, 2006). Moreover, different time scales are used by different studies to estimate additional reserve requirements. Additionally, some studies consider only operating costs whereas others take into consideration investments for new reserves. Another reason for these discrepancies is the fact that some studies consider transmission possibilities to maintain the supplydemand balance while others do not.

In spite of the scattered results, one can draw the following conclusions:

* The incremental cost of balancing requirement is low at low wind penetration levels and increases with higher wind penetration levels (Holttinen, 2006). At high penetration levels the cost of required reserves is significantly less when considering the net load variations (load - wind) compared with wind power variability. 
* The flexibility of conventional (dispatchable) generation plays a crucial role in reducing wind power integration costs. Therefore, hydro dominated countries, eg. Norway, have lower costs than thermal stations dominated countries, eg. Germany. The coordination of the operation of hydro generating systems with the electricity produced from wind farms opens up new possibilities to the system operators and utilities. The output of wind facilities can be stored in water reservoirs and delivered later at times when needed most (Gil and Joss, 2006).

* Available transmission capacities to neighboring systems, eg. Denmark, facilitate the increase in wind penetration levels without increasing balancing requirements to a certain extent. For example, the Greennet study expected balancing costs of $\$ 0.65$ per MWh wind production at $67 \%$ penetration level (peak wind production / peak demand) (Meibom, 2006). Nevertheless, wind power integration costs increases when a neighboring country gets more wind power because exporting possibilities decrease.

* To minimize integration costs, wind power production facilities should be geographically dispersed especially when transmission capacity is limited. Germany has a relatively high integration costs compared with Denmark, Norway and Sweden because of concentration of wind power production in north-west region (Holttinen, 2006).

\section{Conclusions}

Due to improved wind turbines technologies and environmental concerns about other competing source of energy, there is a strong growth of wind power capacity around the globe. However, wind power is of intermittent nature. Therefore, to maintain high reliability in presence of wind power, system operator should consider wind generation capacity during high and low wind conditions, system robustness to survive a fault, reserve and ramping capabilities, transmission capacity, control or down regulation of available wind power. Recent studies show that the dominant wind integration cost component occurs in the unit commitment time frame due to the uncertainty and variability of wind production. However, available forecasting tools can provide about $80 \%$ of benefits that would have been gained from perfect forecasting.

Although wind power integration cost is highly system dependent, one can conclude that these costs increase as wind penetration level increases. The flexibility of existing dispatchable generation units and the available transmission capacity to neighboring areas play a key role in reducing integration costs. Additionally, a wider geographical dispersion of wind power turbines results in a lower integration costs.

\section{Acknowledgment}

M. H. Al-Badi gratefully acknowledges the financial support received from Sultan Qaboos University, Muscat, Oman, for supporting his $\mathrm{PhD}$ program at the University of Waterloo, ON, Canada.

\section{References}

Ackermann, T., 2005, "Wind Power in Power Systems," Chichester, John Wiley \& Sons.

Corp, E. and Inc, W., 2004, " Characterization of the Wind Resource in the Upper Midwest," Wind Integration Study-Task 1.

Energy, G., 2006, Ontario Wind Integration Study - A report prepared for Ontario Power Authority (OPA) Independent Electricity System Operator (IESO) and the Canadian Wind Energy Association (CanWEA).

Energy, G., 2005, " The Effects of Integrating Wind Power on Transmission System Planning," Reliability, and Operations: Report on Phase 2, Prepared for The New York State Energy Research and Development Authority.

Gil, H.A. and Joss, G., 2006, "Integration of Wind Generation with Power Systems in Canada: overview of Technical and economical impacts," CANMET Energy Technology Centre - Varennes CETC 2006-016.

Holttinen, H., 2006, " Design and Operation of Power Systems with Large Amounts of Wind Power," first results of IEA collaboration, in Global Wind Power Conference Adelaide, Austrlia.

Hoven, V.d., 1957, "Power Spectrum of Horizontal Wind Speed in the Frequency Range from 0.0007 to 900 Cycles Per Hour," J. Metrology, Vol. 14, pp. 160-164.

Inc, H.E., 2006, Analysis Of Future Wind Farm Development In Ontario - A report prepared for Ontario Power Authority.

ILEX and UMIST, 2002, Quantifying the System Costs of Additional Renewables in 2020.

Meibom, P., Weber, C., Barth, R. and Brand, H., 2006, " Operational Costs Induced by Fluctuating Wind Power Production in Germany and Scandinavia," Deliverable D5b - Disaggregated System Operation Cost and Grid Extension Cost Caused by Intermittent RESE grid integration, GreenNetEU27. 
The Journal of Engineering Research Vol. 7 No. 2 (2010) 24-31

Quezada, V. and e. al. 2006, "Assessment of Energy Distribution Losses for Increasing Penetration of Distributed Generation," IEEE T Power Syst, Vol. 21, pp. 533-540.

Smith, J.C., Milligan, M.R., DeMeo, E.A. and Parsons, B., 2007, " Utility Wind Integration and Operating Impact State of the Art, IEEE T Power Syst, Vol. 22, pp. 900-908.

Smith, J.C., Milligan, M.R., DeMeo, E.A. and Parsons, B., 2004, "Wind Power Impacts on Electric Power System Operating Costs: Summary and Perspective on Work to Data," in the American Wind Energy Association Global Wind Power Conference Chicago, Illinois.

Soder, L., Hofmann, L., Orths, A., Holttinen, H.A., Wan, WAYA and Tuohy, A.A.T.A., 2007, " Experience From Wind Integration in Some High Penetration Areas," IEEE T Energy Conver, Vol. 22, pp. 4-12.

TrueWind, A., 2005, "An Analysis of the Impacts of
Large-Scale Wind Generation on the Ontario Electricity System.

The North American Electric Reliability Corporation (NREC) (NREC), Reliability Standards, http://www.nerc.com.

Ummels, B.C., Gibescu, M., Pelgrum, E., Kling, W.L. and Brand, A.J., 2007, "Impacts of Wind Power on Thermal Generation Unit Commitment and Dispatch," IEEE T on Energy Conver, Vol. 22, pp. 44-51.

World Wind Energy Association, Wind turbines generate more than $1 \%$ of the global electricity, Bonn 21 February 2008.

Zavadil, R., King, J., Xiadong, L., Ahlstrom, M., Lee, B., Moon, D., Finley, C., Alnes, L., Jones, L., Hudry, F., Monstream, M. and Lai, S., 2004, " Wind Integration Study- Final Report," J. Smith Xcel Energy, Minnesota Department of Commerce, EnerNex Corporation, and Wind Logics Inc. 